\title{
Investigation on the Rate of Solidification and Mould Heating in the Casting of Commercially Pure Aluminium in Permanent Moulds of varying Thicknesses
}

\author{
K. C. Bala ${ }^{1}$, R. H. Khan ${ }^{2}$, M. S. Abolarin ${ }^{3}$ and O. K. Abubakre ${ }^{4}$ \\ 1, 2, 3, ${ }^{4}$ Mechanical Engineering Department, Federal University of Technology, P.M.B. 65, Minna, Nigeria
}

\begin{abstract}
The quality of casting in the foundry can be measured by the rate at which solidification of the molten metal takes place, which is consequent upon the rate the mould, is able to dissipate the heat of solidification to the surroundings. The faster or slower the heat removal process during solidification the structure of the grains formed by the casting is either finer of coarser. An experimental investigation was carried out to compare the rate of solidification of commercially pure aluminium in metallic moulds. The rate at which solidification occurred was compared with the rate at which the mould absorbed and dissipates heat. The experiments conducted recorded the temperature fields at different casting location and that of the moulds respectively. The results showed that there is a direct relation of the rate of heat absorption by the mould and the rate of solidification in metallic moulds.
\end{abstract}

Keywords - Aluminium, casting, heat, mould, solidification, temperature.

\section{INTRODUCTION}

Solidification of casting in permanent (metallic) mould is much faster than in sand mould due to its high thermal conductivity. The rate of heat transfer is controlled at the interface between the solidifying metal and the metallic mould where air gap quickly develops [1]. Rate of heat transfer between a solidifying casting and mould is critical for achievement of a high quality casting. This is especially important in permanent mould casting where the heat transfer between the casting and the mould are primarily controlled by conditions at the mould-metal interface. At the metal-mould interface the casting tends to shrink as it solidifies, creating areas where gaps form between the casting and the mould surface [2]. Solidification involves extraction of heat from the molten metal thereby transforming it to solid state at the solid-liquid interface. The rate of solidification is determined mainly by rate of heat extraction through conduction and convection and can be represented using cooling curves [3].

This research was to study the temperature distribution in aluminium cast as well as that in the metallic mould during the process of solidification. Solidification phenomenon was investigated from heat transfer perspective in order to contribute to a better understanding of the solidification process in the casting of aluminium in permanent moulds. Permanent mould casting is the casting of metals by continually using a reuseable mould, thus making casting time much shorter than in temporary sand casting. Permanent mould casting can be gravity die casting; centrifugal casting; and die casting [4]. Metallic moulds are of permanent nature and are used repeatedly for casting process without getting damaged, unlike sand moulds which are serviceable only once, as they have to be destroyed to extract the casting. Metallic moulds give superior surface characteristics and can produce castings to close tolerances, which ensures better mechanical properties, resistance to corrosion and with distinctive surface finish as against that of sand mould. Rapid solidification nature of permanent mould permits almost immediate shakeout of castings, greatly reducing production cycle time and improving mechanical properties of cast parts [5]. A large quantity of small-sized castings, particularly those in aluminium and magnesium is cast in permanent moulds. In permanent mould casting, the metal and the mould are practically inert towards each other. Apart from the normal oxidation of the surface of the casting by the air, there are no significant chemical reactions which are an added advantage of metallic moulds.

\subsection{Pure Metal Solidification}

Pure metals have clearly defined melting or freezing points, and their solidification takes place at a constant temperature as shown in Fig. 1. Solidification begins at the melting temperature and continues to form a thermal arrest - a plateau on the cooling curve during the solidification of a material caused by the evolution of the latent heat of fusion [6]. 


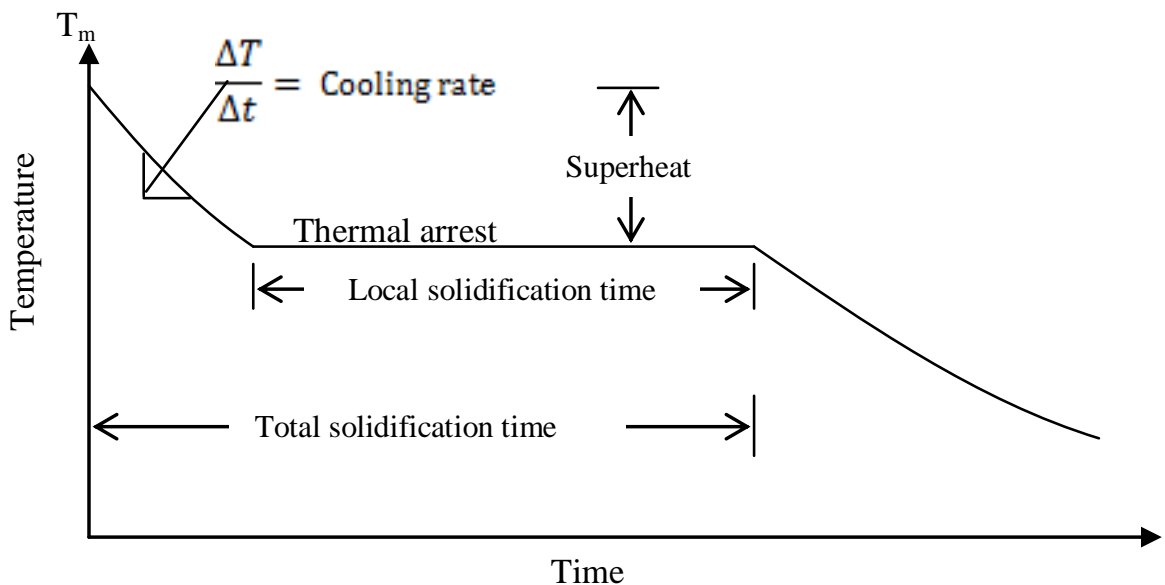

Figure 1: Cooling curve for a pure metal.

Due to chilling action of mould wall, a thin skin of solid metal is formed at the interface immediately after pouring. Randomly oriented grains of small size form near the mold wall, and large columnar grains oriented toward the centre of the casting form later. The solid-liquid interface moves through the molten metal from the mould walls inward to the centre. Once solidification has taken place at any point cooling resumes. The solidified metal, called the casting, is then taken out of the mould and begins to cool to ambient temperature.

\section{MATERIALS AND METHOD}

Casting process was conducted in a top poured rectangular shaped metallic mould made from low carbon steel. The mould cavity has length of 100 , breadth of $50 \mathrm{~mm}$ and a depth of $100 \mathrm{~mm}$. Three moulds of thicknesses 12.5, 25.0 and $37.5 \mathrm{~mm}$ were used. The thermophysical properties of metallic moulds are shown in Table 1.

Table 1. Thermo-physical properties of steel mould [7]

\begin{tabular}{|c|l|l|}
\hline Symbol & \multicolumn{1}{|c|}{ Properties } & Values \\
\hline $\mathrm{K}_{\mathrm{st}}$ & Thermal conductivity $\left(\mathrm{W} / \mathrm{m}^{\circ} \mathrm{C}\right)$ & 78.2 \\
$\mathrm{C}_{\text {st }}$ & Specific heat capacity $\left(\mathrm{J} / \mathrm{kg}^{\circ} \mathrm{C}\right)$ & 456 \\
$\rho_{\text {st }}$ & Density $\left(\mathrm{kg} / \mathrm{m}^{3}\right)$ & 7870 \\
$\mathrm{~h}_{\text {st-air }}$ & Heat transfer coefficient $\left(\mathrm{J} / \mathrm{sec}^{2}{ }^{\circ} \mathrm{C}\right)$ & 9.93 \\
\hline
\end{tabular}

\subsection{EXPERIMENTAL SETUP}

Temperature profiles in both the cast and the mould were monitored and recorded with RD8900 paperless digital recorder during the casting experiment by mounting five K-type (Chromel/Alumel) thermocouples at a depth of $50 \mathrm{~mm}$ from the top surface of the mould as shown in Fig. 2. Thermocouples AI1, AI 2 were fixed in the cast, AI3 was fixed at the cast/mould interface, AI4 in the mould, and AI5 fixed in the mould-air interface.

$\begin{array}{lll}\text { AI1 } & - & \text { Centre of casting } \\ \text { AI2 } & - & \text { Half cast thickness } \\ \text { AI3 } & - & \text { Metal - Mould interface } \\ \text { AI4 } & - & \text { Half mould thickness } \\ \text { AI5 } & - & \text { Mould-Air interface }\end{array}$




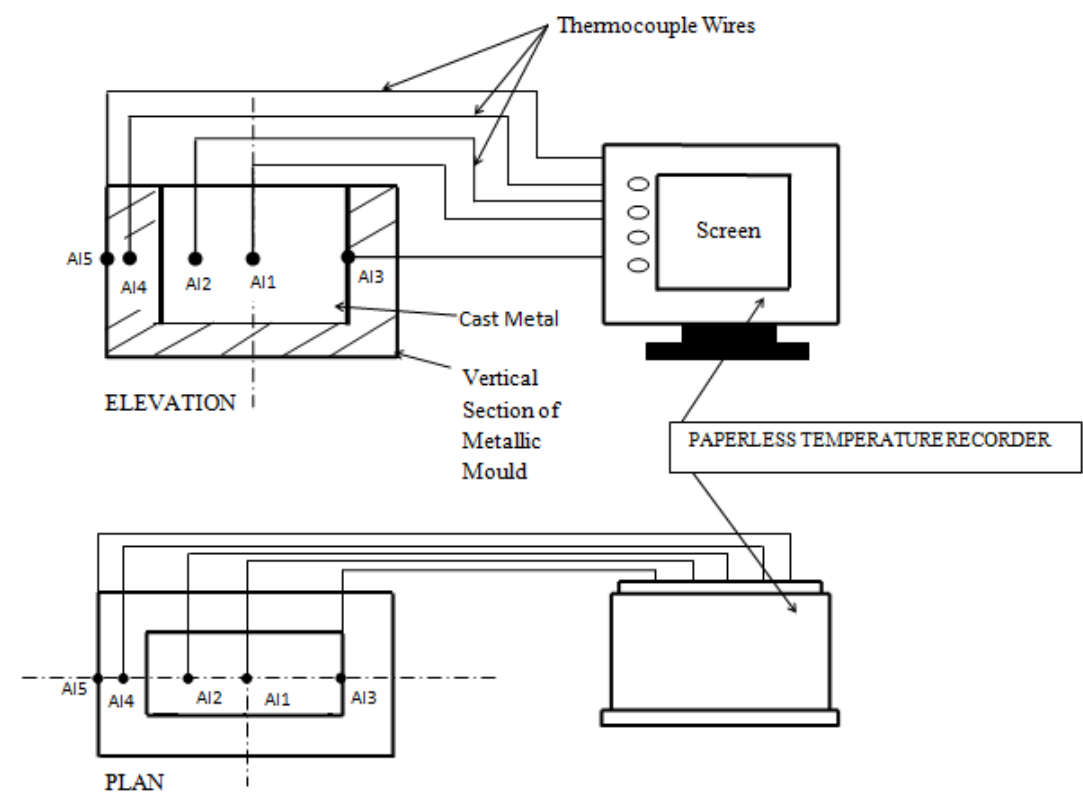

Figure 2: Schematic diagram of experimental setup for rectangular mould .

\subsection{CHEMICAL COMPOSITION}

The casting was made from commercially pure aluminium obtained by melting electrical aluminium conductors in a resistance furnace. The chemical composition is given in Table 2.

Table 2: Chemical Composition of Commercially Pure Aluminium in Percent

\begin{tabular}{|c|c|c|c|c|c|c|}
\hline $\mathrm{Si}$ & $\mathrm{Mn}$ & $\mathrm{S}$ & $\mathrm{Zn}$ & $\mathrm{Ni}$ & $\mathrm{P}$ & $\mathrm{Al}$ \\
\hline 0.06 & 0.03 & 0.002 & 0.03 & 0.002 & 0.03 & 99.846 \\
\hline
\end{tabular}

\subsection{MOULDS SPECIFICATION}

To investigate the rate of solidification and mould heating, moulds specifications for the rectangular moulds are shown in Table 3.

Table 3. Dimensions of rectangular moulds and cast

\begin{tabular}{|c|c|c|c|}
\hline Mould wall thickness (mm) & Length of Cast (mm) & Width of Cast (mm) & $\begin{array}{l}\text { Depth of Cast } \\
(\mathrm{mm})\end{array}$ \\
\hline 12.5 & 100 & 50 & 100 \\
25.0 & 100 & 50 & 100 \\
37.5 & 100 & 50 & 100 \\
\hline
\end{tabular}

The design of the moulds was done to ensure that unidirectional heat flow is dominant during solidification. During the experiment all the vertical faces of the mould were exposed, while the top and the bottom were insulated.

The aluminium conductors were collected and heated in an electric resistance furnace until it melted and reached a pouring temperature of $720^{\circ} \mathrm{C}$. The pouring temperature was monitored by dipping a $\mathrm{K}$ - type thermocouple connected to digital multimeter as well as using the temperature indicator of the furnace. Ash from burnt torch batteries as a substitute for a sodium modifier was added during the process of melting. The molten aluminium in the crucible was poured into the mould cavity within 5 seconds. The moulds were kept at an initial temperature of $33.6^{\circ} \mathrm{C}$ and the molten aluminium poured at $720^{\circ} \mathrm{C}$. The solidification time for each thickness was obtained from the plot of graphs from the Paperless Temperature Recorder

\section{RESULTS AND DISCUSSION} follows:

The experimental results recorded using R8900 digital recorder, are shown in the Fig.3, 4 and 5 that 


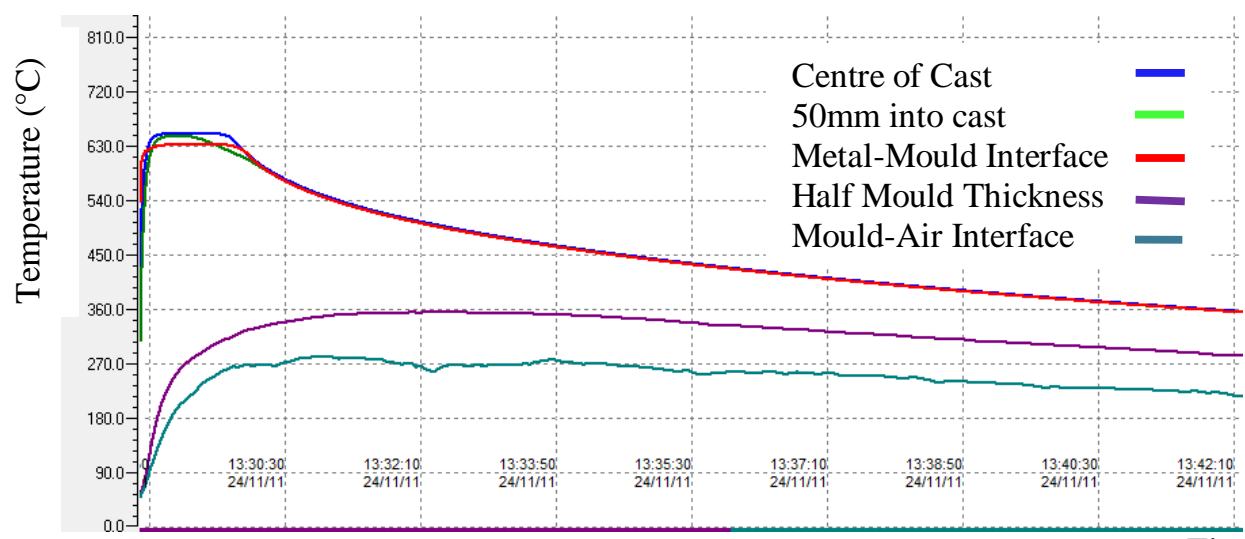

Time (sec)

Figure 3: Cooling and heating curves at varying aluminium cast and mould locations for $12.5 \mathrm{~mm}$ thick rectangular metallic mould for the solidification of commercially pure aluminium

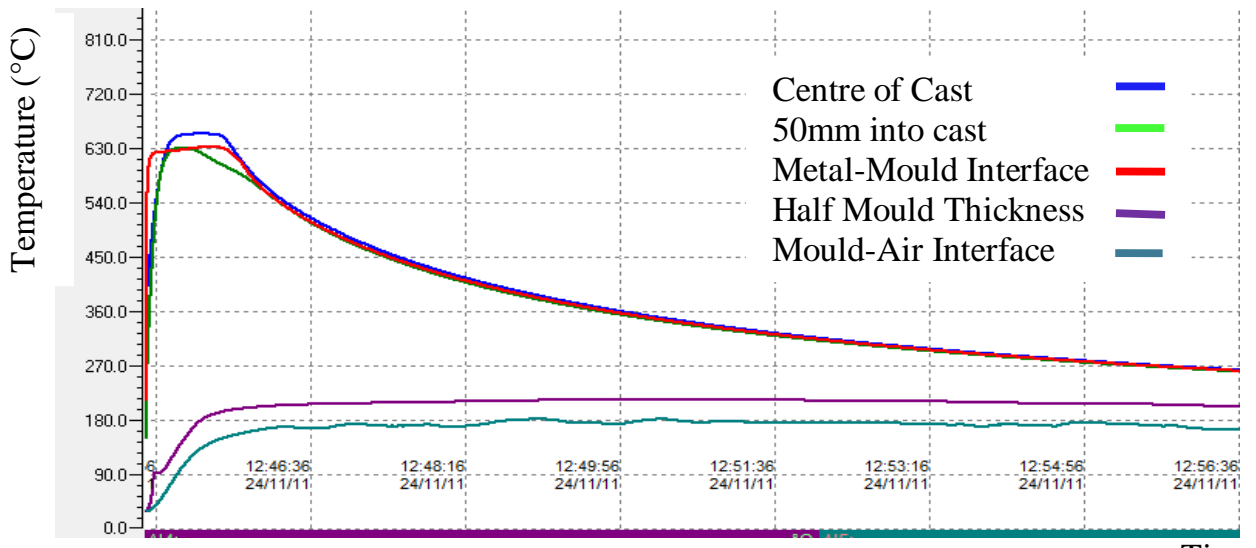

Time (sec)

Figure 4: Cooling and heating curves at varying aluminium cast and mould locations for $25.0 \mathrm{~mm}$ thick rectangular metallic mould for the solidification of commercially pure aluminium

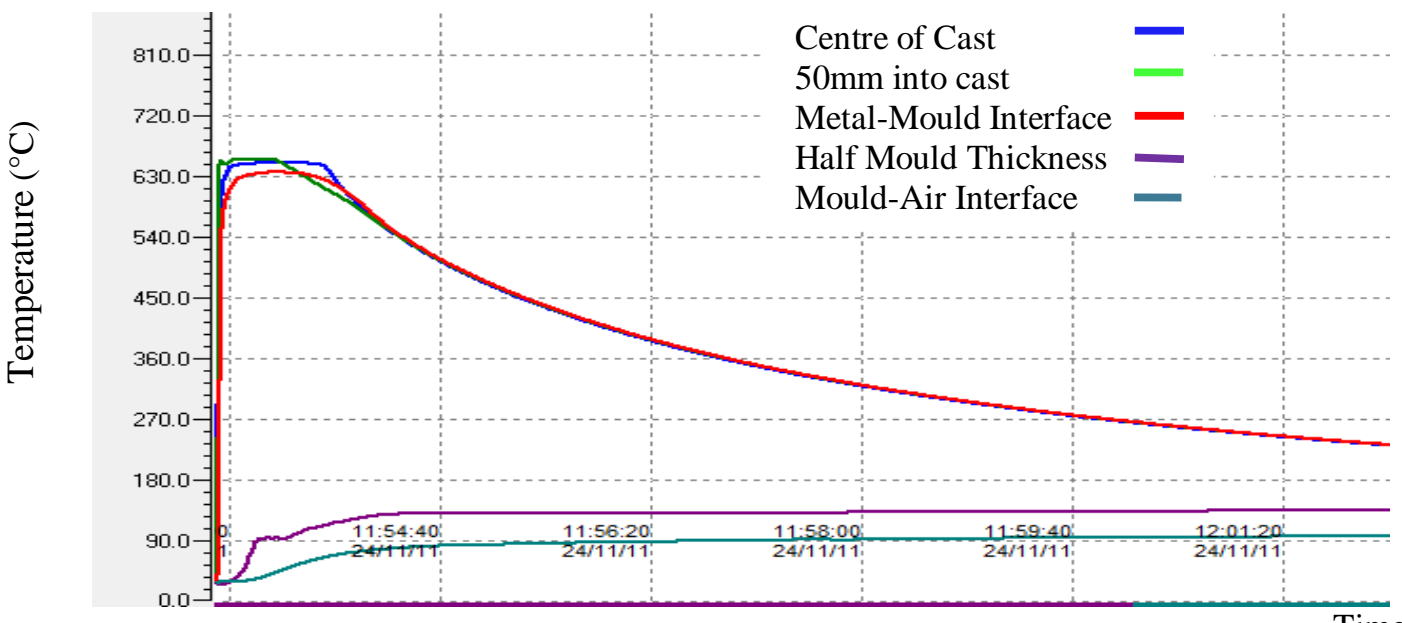

Time (sec)

Figure 5: Cooling and heating curves at varying aluminium cast and mould locations for $37.5 \mathrm{~mm}$ thick rectangular metallic mould for the solidification of commercially pure aluminium.

Fig. 3, 4 and 5 give the solidification (cooling curves) of the aluminium cast and the mould heating curves during the casting process using the commercially pure aluminium of $99.846 \%$ in rectangular moulds of thicknesses of $12.5,25.0$, and $37.5 \mathrm{~mm}$ respectively. A close examination of the cooling curves shows that at the metal/mould interface the temperatures continue to fall rapidly for several degrees and thereafter relatively slowly. At the centre of the aluminium cast, the liquid aluminium metal cools quickly to the freezing temperature of approximately constant temperature of $655.5^{\circ} \mathrm{C}$ for the three mould thicknesses. There is a 
measurable thermal arrest at this location indicating the solidification time of the aluminium cast. Table 3 presents the solidification time of the aluminium cast increasing as the mould thickness increases. This indicates that the solidification period is longer in thicker moulds.

Table 3: Variation of Solidification Time with Mould Thickness in Rectangular Mould for Commercially Pure Aluminium

\begin{tabular}{|c|c|c|c|}
\hline $\begin{array}{c}\text { Mould Temperature } \\
\left({ }^{\circ} \mathrm{C}\right)\end{array}$ & $\begin{array}{c}\text { Pouring Temperature } \\
\left({ }^{\circ} \mathrm{C}\right)\end{array}$ & $\begin{array}{c}\text { Mould Thickness } \\
(\mathrm{mm})\end{array}$ & $\begin{array}{c}\text { Solidification Time } \\
(\text { seconds })\end{array}$ \\
\hline 33.6 & 720 & 12.5 & 22.8 \\
33.6 & 720 & 25.0 & 26.4 \\
33.6 & 720 & 37.5 & 28.8 \\
\hline
\end{tabular}

From the results of Table 3, the moulds were kept at an initial temperature of $33.6^{\circ} \mathrm{C}$ and the molten aluminium poured at $720^{\circ} \mathrm{C}$. The solidification time for each thickness was obtained from the plot of graphs from the paperless temperature recorder at the point when the solidified aluminium cast started reducing in temperature from the constant value of fusion temperature.

The mould heating curves as obtained at the mould/air interface and half mould thickness are shown in Fig. 3, 4 and 5. Temperature rises rapidly in the $12.5 \mathrm{~mm}$ thick mould of Fig. 3 from the beginning of solidification until it reached a maximum value, it then start decreasing. Whereas a progressive rise in temperature is observed for the thicker moulds of $25.0 \mathrm{~mm}$ and $37.5 \mathrm{~mm}$ as indicated in Fig. 4 and Fig. 5, the temperature increase to a maximum point and then remain slightly constant indicating slow extraction of heat.

\section{CONCLUSION}

A commercially pure aluminium casting experiment was carried out in order to investigate the rate of solidification as well as the rate of heat transfer between the metallic mould and the cast. It is observed that as soon as the aluminium metal was poured into the moulds, the temperature falls rapidly for several degrees and thereafter relatively slowly. The sudden change in the rate of fall in temperature indicates undercooling at the interface. This undercooling is attributed to the latent heat of fusion released when solidification began at the mould wall and was completed at the interface almost instantaneously. Temperature rises rapidly in the $12.5 \mathrm{~mm}$ thick mould from the beginning of solidification until it reached a maximum value, it then start decreasing. Whereas a progressive rise in temperature is observed for the thicker moulds of $25.0 \mathrm{~mm}$ and $37.5 \mathrm{~mm}$ the temperature increase to a maximum point and then remain slightly constant indicating slow extraction of heat. The investigation showed that thinner moulds had higher rate of heat extraction and therefore higher rate of solidification.

\section{Acknowledgements}

We acknowledge the contribution of the Science and Technology Education Post-Basic (STEP-B) Project of the Federal Ministry of Education of Nigeria for the award of Innovators of Tomorrow (IOT) grant which enabled the acquisition of instruments for the experiments.

\section{REFERENCES}

[1] K. C. Bala and R. H. Khan, Experimental Determination of the Effect of Mould Thickness on the Solidification Time of Aluminium Alloy (Al-Mn-Ni -Si) Casting in Rectangular Metallic Moulds, International Journal of Engineering Research \& Technology, 2(3), 2013, 1-6

[2] K. C. Bala, Simulation of Solidification of Aluminium Casting in Metallic Mould, doctoral diss., Mechanical Engineering Department, Federal University of Technology, Minna, Nigeria, 2012.

[3] R. E. P. DeGarmo, J. T. and R. A. Kohser, Materials and Processes in Manufacturing (New York, John Wiley \& Sons, 2010).

[4] P. L. Jain, Principles of Foundry Technology (London: McGraw-Hill, 2003).

[5] Y. S. Lerner, Permanent Mold Casting of Ductile Iron, Journal of Foundry Management \& Technology, 131(10), 2003, 18 - 22.

[6] R. Swarnkar, R. Kumar, R. M. Paswan, S. Singh, and V. Goyal, Modelling of Heat Transfer in Solidification Process. Term Paper Report, Department of Mechanical Engineering, Indian Institute of Technology, Guwahati, 2004.

[7] C. A. Santos, J. M. V. Quaresma, and A. Gracia, Determination of Transient Interfacial Heat Transfer Coefficients in Chill Mold Castings, Journal of Alloys and Compounds, 3(19), 2001, 174 - 186. 